\title{
ASPECTOS BIOLÓGICOS E SUAS IMPLICAÇÕES NA PRODUÇÃO MASSAL DE Chrysoperla externa HAGEN, 1861 (NEUROPTERA: CHRYSOPIDAE)
}

\author{
Guilherme Frateschi Trivellato ${ }^{1}$, Evoneo Berti Filho ${ }^{2}$, Marcelo Poletti ${ }^{3}$ \\ ${ }^{1}$ Mestre em Entomologia - ESALQ/USP, e-mail: trivellato@gmail.com \\ ${ }^{2}$ Depto. Entomologia e Acarologia - ESALQ/USP - Caixa postal 9, CEP 13.418-900, Piracicaba, SP, e-mail: eberti@usp.br \\ ${ }^{3}$ PROMIP - Comércio, Pesquisa e Desenvolvimento de Agentes Biológicos Ltda.
}

\section{RESUMO}

Com o objetivo de incentivar novos pesquisadores e empreendedores da área de controle biológico de pragas, foi realizada uma série de experimentos voltados à qualidade da produção massal do agente biológico Chrysoperla externa (Neuroptera: Chrysopidae). Estudaram-se aspectos biológicos dessa espécie, visando delinear um sistema de produção eficiente, baseado em 7 módulos de gaiolas de adultos, onde foram coletados ovos por 49 dias. Para manter produtividade constante, esses módulos são montados com uma diferença de tempo de 7 dias entre eles. Outras técnicas de produção e comercialização também estão descritas.

Palavras-chave: Biologia, insetos predadores, controle biológico, qualidade

\section{BIOLOGICAL ASPECTS AND THEIR INFLUENCE ON THE MASS PRODUCTION OF Chrysoperla externa HAGEN, 1861 (NEUROPTERA: CHRYSOPIDADE)}

\begin{abstract}
This research deals with biological aspects and their influence on the quality of Chrysoperla externa (Neuroptera; Chrysopidae) produced in laboratory. The system of production was based on seven modules of adult cages from which are collected eggs during 49 days. Such modules must be prepared at each seven days to provide a constant flowing production. Other techniques of production and commercialization are described as well.
\end{abstract}

Keywords: Biology, predator insects, biological control, quality

\section{INTRODUÇÃO}

Entre as técnicas que visam ao controle de insetos-praga nas lavouras, destaca-se o Manejo Integrado de Pragas (MIP), baseado em um conjunto de táticas que visam à prevenção, ao monitoramento e ao tratamento contra insetos-praga, em culturas perenes e anuais. O MIP não oferece receita específica, sendo necessário que se avalie cada caso isoladamente. Entre os métodos de controle que compõem o MIP, destaca-se o Controle Biológico (CB), definido por DeBach (1974) como "a ação de parasitos, predadores ou patógenos que mantém a densidade populacional de outros organismos numa média mais baixa do que ocorreria na sua ausência". Nos diferentes agroecossistemas o CB é um processo natural e dinâmico, resultante da ação de insetos entomófagos (parasitoides e 
predadores) e de agentes entomopatogênicos.

Entre os insetos predadores, a ordem Neuroptera destaca-se, principalmente, pela família Chrysopidae que tem papel importante no controle de insetos-praga. No Brasil, destaca-se a espécie Chrysoperla externa, por causa da sua ampla distribuição e volume de pesquisas já realizadas. Esses insetos, importantes agentes do controle biológico natural, podem ser utilizados no controle biológico aplicado, por meio de liberações massais. Ribeiro (1998), porém, ressalta que muitos aspectos da bioecologia desses insetos ainda são desconhecidos; daí a importância de estudos que resultem na sua plena utilização em benefício da agricultura moderna.

O presente trabalho teve por meta não só o estudo de fatores biológicos, técnicas de produção e custos envolvidos, mas ainda o fornecimento de informações que garantam uma produção eficaz e viável de Chrysoperla externa e aprimorem técnicas de produção.

Os crisopídeos são importantes predadores encontrados em muitas culturas de interesse econômico como algodoeiro, citros, milho, soja, alfafa, fumo, videira, macieira, seringueira e outras. Podem alimentar-se de ovos, lagartas neonatas, pulgões, cochonilhas, ácaros e vários outros artrópodes de pequeno tamanho e de tegumento facilmente perfurável (Carvalho \& Souza, 2000). Nos sistemas agrícolas, são encontrados alimentando-se de Helicoverpa armigera (Hübner), Heliothis virescens (Fabricius), Helicoverpa zea (Boddie), Spodoptera littoralis (Boisduval) (Lepidoptera: Noctuidae), Bemisia tabaci (Gennadius) (Hemiptera: Aleyrodidae) e Aphis gossypii Glover (Hemiptera: Aphididae). No Brasil, Chrysoperla externa e Ceraeochrysa cubana destacam-se em estudos de biologia voltados a programas de controle integrado de pragas (Freitas \& Fernandes, 1996).
O gênero Chrysoperla Steinmann, 1964, é provavelmente o mais estudado da família Chrysopidae. No Brasil, são encontradas quatro espécies desse gênero: $C$. externa (Hagen, 1861); C. defreitasi (Brooks, 1994); C. raimundoi (Freitas \& Penny, 2001) e, mais recentemente, uma nova espécie, C. genanigra (Freitas, 2003). Contudo, C. externa é possivelmente a mais comum da região Neotropical (Freitas \& Penny, 2001), e tem sido amplamente estudada nos últimos anos, por predar diversas pragas presentes em agroecossistemas. No Brasil, Chrysoperla externa e Ceraeochrysa cubana destacam-se em estudos de biologia, direcionados a futuros programas de controle integrado de pragas (Freitas, 2001).

O sucesso da produção comercial de agentes biológicos e do controle biológico depende basicamente de três fatores: a seleção de um organismo benéfico, seu uso eficiente e sua qualidade superior. Caso um desses fatores não atinja um potencial mínimo necessário, o controle biológico de pragas será ineficiente e ineficaz. Quem pretende, portanto, investir em controle biológico de pragas deve considerar os três fatores do sucesso para se manter ativo nos mercados (Lenteren, 2000).

Programas de criação massal de inimigos naturais têm passado, ao longo dos anos, por marcantes e consideráveis mudanças. Para se minimizarem alguns desequilíbrios, recomendam-se constantes adequações no sistema de produção, destacando-se tipo e qualidade da presa utilizada como fonte de alimento, temperatura, umidade, fotoperíodo e recipiente de criação, entre outros fatores, buscando assim obter indivíduos com características desejáveis para o controle biológico.

Os crisopídeos vêm despertando interesse como agentes biológicos há bastante tempo. Os estudos voltados à multiplicação massal desses insetos 
iniciaram-se no final da década de 40 com Finney. Desde então muitos avanços foram obtidos por pesquisadores de diversos países, sendo que um dos melhores apanhados das técnicas de produção foi feito por Freitas (2001), que publicou um manual de criação de crisopídeos em laboratório, com destaque em todos os processos produtivos, desde a criação do alimento, passando pelas técnicas de criação das fases imaturas, até as ferramentas utilizadas na coleta de ovos. Esse manual serve até hoje de referência para todos aqueles que pretendem iniciar uma produção massal desses insetos. Infelizmente, na literatura nacional, muitos trabalhos não apontam alguns detalhes importantes como rendimento operacional das etapas envolvidas.

Dada a sua facilidade de criação em laboratório e de larvas com alta capacidade predatória, a utilização de $C$. externa em programas de controle biológico é promissora, uma vez que esse crisopídeo apresenta alto potencial reprodutivo e eficiência como predador de insetos-praga de várias culturas (Carvalho et al., 1996; Bezerra et al., 2006;). Bezerra et al. (2009) ressalvam, entretanto, que estudos sobre os dados obtidos em condições de laboratório ainda são escassos, e que o estudo de seus aspectos biológicos em condições de laboratório serve de base para se adaptar ao sistema de produção em escala massal.

$\mathrm{O}$ sucesso de um programa de controle biológico depende da disponibilidade de agentes para liberação em larga escala. Numa criação massal, devem ser considerados fatores intrínsecos e extrínsecos (Carvalho \& Souza 2000; Freitas 2001). Fatores intrínsecos são aqueles relacionados à fisiologia do inseto como adaptabilidade a dietas, potencial reprodutivo, fecundidade, fertilidade e ainda efeitos nutricionais. Quanto aos fatores extrínsecos podem se considerar as técnicas utilizadas para manipulação dos insetos, materiais empregados, manipulação das fases de desenvolvimento, controle de qualidade e custos de produção. É imprescindível que, em um sistema de produção, os fatores extrínsecos estejam adequados aos fatores intrínsecos, de forma a se aperfeiçoar a produção do inseto.

\section{MATERIAL E MÉTODOS}

A metodologia a seguir, sobre a produção massal de crisopídeos no Brasil, foi desenvolvida por Freitas (2001). A obtenção dos insetos matrizes deve ser realizada na área onde se pretende liberar os predadores, para se minimizarem os problemas de adaptação a diferentes ambientes. Quanto maior o número de matrizes da mesma espécie obtidas, antes de se iniciar a produção, melhor será $\mathrm{o}$ desempenho e menor será a deterioração da população em condições de laboratório. Os insetos adultos são mantidos na razão de 1:1 (machos : fêmeas) em gaiolas de PVC forradas com papel sulfite internamente e fechadas com tela de voil ou tule nas duas extremidades. A tela da parte superior da gaiola tem uma abertura onde se apoia o alimentador composto por um pequeno frasco cheio de água. Uma espuma na sua ponta recebe uma dieta composta por mel, levedo de cerveja e água e, com o auxílio de uma borracha, o frasco se sustenta com a boca voltada para baixo, alimentando os insetos adultos. As posturas de crisopídeos, muito características, são compostas por um pedúnculos de cerca de $10 \mathrm{~mm}$, fixo a um substrato, na extremidade dos quais cada ovo fica suspenso. Nas gaiolas, os ovos são colocados sobre a folha de sulfite que as reveste internamente. Com o auxílio de uma lâmina, os ovos são raspados e separados para posterior comercialização ou multiplicação da população de laboratório. No caso da multiplicação, os ovos são colocados em potes com no mínimo $300 \mathrm{ml}$ de volume, cheios de papel dobrado, para aumentar a área disponível de caminhamento 
das larvas e, consequentemente, diminuir o canibalismo. Para a alimentação das larvas são utilizados ovos de traças como Anagasta kuehniella Zeller, (Lepidoptera, Pyralidae) e Corcyra cephalonica Stainton (Lepidoptera, Pyralidae), porém os melhores resultados têm sido observados com a utilização de ovos de Sitotroga cerealella Olivier (Lepidoptera, Gelechiidae). Os experimentos foram realizados em salas climatizadas a 25 $\pm 2^{\circ} \mathrm{C}, 60 \pm 10 \%$ UR e fotofase de 14 horas.

A fim de determinar o período de incubação e a viabilidade dos ovos foram analisados 210 ovos, não tratados assepticamente, da segunda postura de 25 fêmeas isoladas. Os ovos foram individualizados em placas para se evitar canibalismo das larvas.

A duração de cada ínstar e a viabilidade da fase larval foi determinada através de larvas recém-eclodidas colocadas em tubos de vidro $(2,5 \mathrm{~cm}$ de diâmetro x 8,5 $\mathrm{cm}$ de altura) com ovos de traça e vedados com filme de PVC. Foram utilizados 150 tubos com uma larva cada, mantidos em fitotron à temperatura de $25^{\circ} \mathrm{C}$, umidade relativa de $70 \%$ e fotofase de 14 horas.

A duração da fase larval foi determinada com base no período entre a eclosão das larvas e a transformação em pupa. A viabilidade dessa fase foi obtida por meio da avaliação da quantidade de indivíduos que atingiram a fase de pupa.

Para a determinação do número de ínstares, foram observadas as exúvias resultantes das trocas de ínstares. Os dados obtidos foram analisados com médias entre a duração das fases de cada larva.

Para determinar a quantidade consumida pela larva do predador foram isoladas, em placas, 25 larvas de cada um dos 3 ínstares (tratamentos) e foram oferecidos ovos de A. kuehniella para cada tratamento, garantindo uma quantidade maior do que o inseto é capaz de consumir. Após um período de 24 horas, os insetos foram retirados e foi contado o número de ovos furados e vazios, caracterizando o consumo por $C$. externa. Os dados obtidos foram analisados com médias obtidas em cada um dos tratamentos (instares) multiplicando-os com a duração média de cada ínstar.

A viabilidade e a duração da fase pupal foram determinadas com base no número de indivíduos e no período compreendido entre a formação do casulo e a emergência dos adultos.

Os adultos foram avaliados quanto a longevidade de machos e fêmeas, período de pré-oviposição e fecundidade de fêmeas. Os adultos recém-emergidos foram separados em 25 casais mantidos isoladamente conforme descrito anteriormente.

Para conhecer alguns fatores que afetam a qualidade e a produção de Chrysoperla externa foi desenvolvido um experimento em parceria com a empresa PROMIP Comércio Pesquisa e Desenvolvimento de Agentes Biológicos Ltda., com insetos coletados no campus da ESALQ/USP, em áreas dominadas por capim do gênero Brachiaria. Os insetos coletados foram mantidos em laboratório e reproduzidos, visando à produção massal de larvas desse predador, para posterior comercialização.

Para a comercialização dos insetos foram testadas embalagens de diversos materiais:

- Embalagem plástica flexível;

-Embalagem de papel plastificada internamente;

- Embalagem de TNT (Tecido Não Tecido) costurado;

- Embalagem de TNT selado por calor;

- Embalagem plástica rígida de $300 \mathrm{ml}$;

- Embalagem plástica rígida de $1000 \mathrm{ml}$.

Para selecionar a melhor embalagem foram considerados fatores como fuga de insetos, integridade dos ovos e viabilidade de larvas.

As embalagens receberam um preenchimento para aumentar seu volume 
interno, permitindo, assim, manter os insetos vivos e distantes uns dos outros. Foram testados os seguintes volumosos:

- Maravalhas de madeira;

- Vermiculita;

- Papel picado;

- Palha de arroz (tratada previamente com inseticida à base de fosfina).

O período de incubação é próximo de 4 dias. A avaliação foi feita controlando a quantidade de ovos colocados por embalagem e fazendo correlação com a quantidade de larvas vivas, 5 dias depois de embalados os ovos, momento ideal de abertura da embalagem. Com cada volumoso, as embalagens receberam alimento alternativo (presas) para as larvas de crisopídeos após a eclosão, diminuindo consequentemente o canibalismo.

Foram testadas as seguintes presas:

-Tyrophagus putrescentiae (Acari: Astigmata) vivos;

- T. putrescentiae mortos por congelamento;

- Ovos de Anagasta kuehniella (Lepidoptera: Pyralidae) inviabilizados;

- Ovos de Sitotroga cerealella (Lepidoptera: Gelechiidae) inviabilizados.

A qualidade das presas como alimento alternativo, foi avaliada por meio da contagem do número de larvas de crisopídeos vivos remanescentes.

Tabela 1. Duração e viabilidade das diferentes fases de desenvolvimento de Chrysoperla externa em condições de laboratório. Temperatura $=25 \pm 10 \mathrm{C}$; UR $=60 \pm 10 \%$ e fotofase $=14 \mathrm{~h}$.

\begin{tabular}{ccc}
\hline Fase & Duração (dias \pm EPM) & Viabilidade $(\% \pm$ EPM) \\
\hline Ovo & $3,70 \pm 0,11$ & $96,88 \pm 1,38$ \\
Larva de $1^{\text {o }}$ ínstar & $3,29 \pm 0,08$ & $83,23 \pm 3,01$ \\
Larva de $2^{\circ}$ ínstar & $3,14 \pm 0,08$ & $95,35 \pm 1,86$ \\
Larva de 3 ${ }^{\circ}$ ínstar & $3,62 \pm 0,09$ & $99,19 \pm 0,81$ \\
Total larval & $10,09 \pm 0,17$ & $78,71+3,30$ \\
Pupa & $10,23 \pm 0,34$ & $92,62+2,38$ \\
\hline Total (ovo - adulto) & $23,91 \pm 0,61$ & $70,63+3,61$ \\
\hline
\end{tabular}

\section{RESULTADOS E DISCUSSÃO}

O período médio de incubação dos ovos da segunda postura foi de 3,7 dias, com viabilidade de $96,88 \%$. Os dados observados para a viabilidade do período larval de $C$. externa foram satisfatórios, considerando-se que a mínima exigida para populações criadas em dieta artificial é de $75 \%$ (Parra, 2007). A temperatura em que os insetos foram mantidos nessa fase foi adequada (Tabela 1).

Para cada ínstar de C. externa o consumo médio de ovos de Anagasta kuehniella foi de 85,80 ovos no primeiro ínstar, 203,39 ovos no segundo e 1179,90 ovos da traça no terceiro (Tabela 2).

A duração média da fase de pupa de C. externa foi de 10,23 dias, com viabilidade nessa fase de 92,62\% (Tabela 1). A duração da fase de pupa e o período total de desenvolvimento de machos e fêmeas não diferiram estatisticamente entre si (Tabela 3). A razão sexual observada para a população estudada foi de 0,532. As fêmeas de $C$. externa apresentaram maior duração da fase adulta, quando comparadas aos machos (Tabela 4). A longevidade dos machos variou de 16 a 81 dias, enquanto a das fêmeas variou de 22 a 85 dias. 
Tabela 2. Consumo médio de ovos de Anagasta kuehniella por C. externa. Temperatura de $25+$ $2^{\circ} \mathrm{C}$ e UR de $70+10 \%$ e fotofase de $14 \mathrm{~h}$

\begin{tabular}{cccc}
\hline & $\begin{array}{c}\text { Consumo diário } \\
(\text { ovos } \pm \text { EPM) }\end{array}$ & Duração do período (dias) & $\begin{array}{c}\text { Consumo no período } \\
\text { (ovos / instar) }\end{array}$ \\
\hline $1^{\circ}$ ínstar & $26,8 \pm 10,54$ & 3,29 & 85,80 \\
$2^{\circ}$ ínstar & $64,77 \pm 26,33$ & 3,14 & 203,39 \\
$3^{\circ}$ ínstar & $325,94 \pm 128,61$ & 3,62 & 1179,90 \\
\hline
\end{tabular}

Tabela 3. Duração média, em dias, da fase pupal e do período de ovo a adulto de machos e fêmeas de Chrysoperla externa em condições de laboratório. Temperatura $=25 \pm 1^{\circ} \mathrm{C}$; $\mathrm{UR}=60 \pm 10 \%$ e fotofase $=14 \mathrm{~h}$

\begin{tabular}{ccc}
\hline Sexo & Pupa (dias) & Ovo - adulto (dias) \\
Macho & $10,22 \mathrm{a}$ & $23,82 \mathrm{a}$ \\
Fêmea & $10,19 \mathrm{a}$ & $23,93 \mathrm{a}$ \\
\hline
\end{tabular}

Valores seguidos de mesma letra na coluna não diferem estatisticamente entre si pelo teste de Tukey $(\mathrm{p} \leq 5 \%)$.

Tabela 4. Duração média do período de pré-oviposição e longevidade de adultos de Chrysoperla externa criadas em laboratório. Temperatura $=25 \pm 10 \mathrm{C}$; UR $=60 \pm 10 \%$ e fotofase $=14 \mathrm{~h}$

\begin{tabular}{cc}
\hline Parâmetro & Duração (dias \pm EPM) \\
\hline Pré-oviposição & $5,86 \pm 0,25$ \\
Macho & $47,42 \pm 3,37 \mathrm{a}$ \\
Fêmea & $55,25 \pm 4,00 \mathrm{~b}$ \\
Média (macho e fêmea) & $51,8 \pm 2,65$ \\
\hline
\end{tabular}

Valores seguidos de letras diferentes na coluna diferem estatisticamente entre si pelo teste de Tukey $(\mathrm{p} \leq 5 \%)$.

O período de oviposição observado foi de 30 dias, enquanto o número médio diário de ovos colocados, por fêmea, foi de 11,28, variando de 1 a 27 por dia.

A oviposição média diária observada variou com a idade dos indivíduos. Os insetos alcançaram a oviposição média de 11,28 ovos diários, a partir do sexto dia de oviposição (Figura 1), ou 9 dias após a emergência dos adultos.

Entre as embalagens testadas, as que apresentaram os melhores resultados, quanto à sobrevivência das larvas, foram as de TNT selado e as embalagens plásticas rígidas, além de serem as de menor custo por unidade. As outras embalagens testadas permitiam a fuga dos insetos.

Para os volumosos testados, a palha de arroz tratada com fosfina foi a que permitiu a maior viabilidade das larvas (Figura 2), além de apresentar baixo custo, estabilidade, permitir boa capacidade de sobreposição de embalagens para transporte e armazenamento e apresentar um formato 


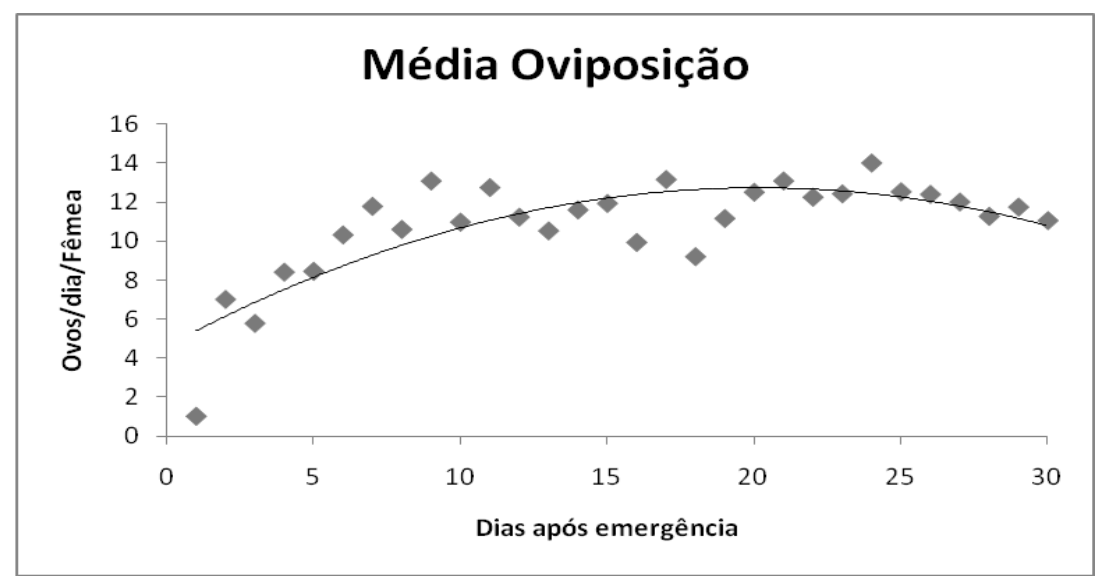

Figura 1. Curva da capacidade de ovoposição média de Chrysoperla externa em condições de laboratório. Temperatura $=25 \pm 10 \mathrm{C} ; \mathrm{UR}=60 \pm 10 \%$ e fotofase $=14 \mathrm{~h}$.

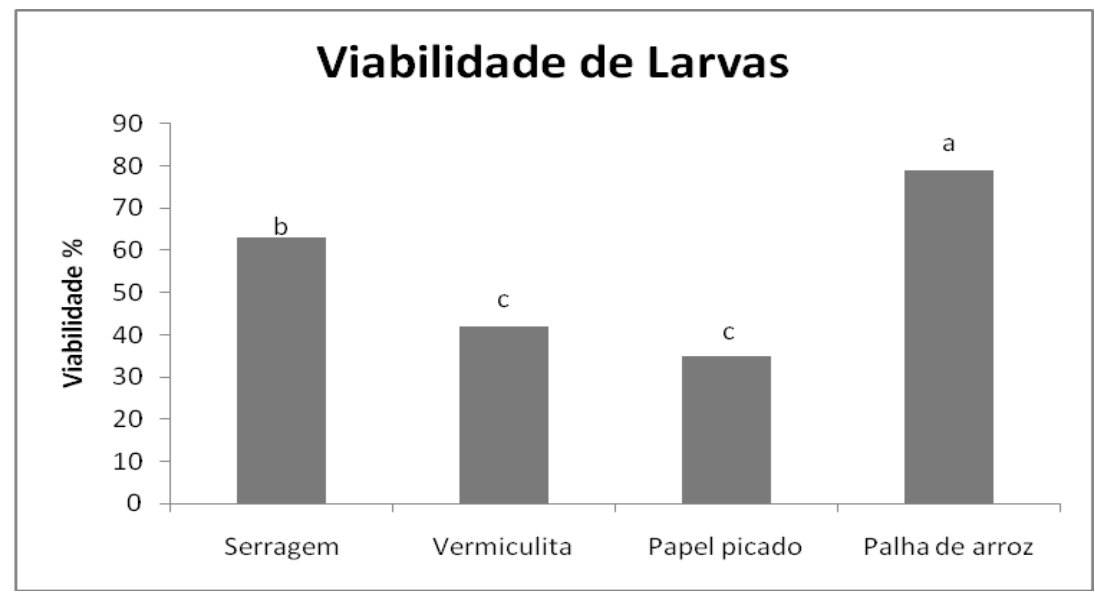

Figura 2. Viabilidade de larvas de Chrysoperla externa após 5 dias em embalagens com diferentes volumosos. Tratamentos seguidos de letras distintas diferem estatisticamente entre si pelo teste de Tukey $(\mathrm{p} \leq 5 \%)$.

de pequenas "conchas" que possibilitam abrigo de ovos e larvas.

Como alimento alternativo oferecido dentro das embalagens, apenas os ovos de traça foram eficientes como alimento dos crisopídeos imaturos. Tyrophagus putrescentiae quando mortos, apesar de custarem menos, não foram suficientes para alimentar as larvas; quando vivos danificaram e mataram as larvas dos insetos no momento em que estas eclodiam ou trocavam de ínstar.

Os ovos das traças se mostraram semelhantes para alimentar as larvas jovens. Foi selecionada Sitotroga cerealella para servir como alimento alternativo em razão do menor preço no mercado.

Com os resultados obtidos foram desenvolvidas duas embalagens, uma em forma de sachê, para a liberação gradual de pequenas porções de insetos, e outra plástica rígida, para distribuição de um maior número de insetos, ambas de baixo custo e que possibilitasse um bom tempo de armazenamento.

Com o auxílio de uma lâmina de estilete presa a um aparelho de barbear (ou estrutura similar) era feita a retirada dos ovos do papel interno da gaiola de produção, o que causava alto índice de perda de ovos, 
além de ser uma operação demorada, pois se requeriam várias passadas do instrumento pela folha de papel. Essa ferramenta foi substituída por uma lâmina única, com cerca de $30 \mathrm{~cm}$ de comprimento, desenhada exclusivamente para caber em uma bandeja plástica. O papel interno é passado uma única vez e os ovos ficam retidos na bandeja. Com esse equipamento, o processo de retirada dos ovos, que levava cerca de 1 hora com alto índice de perdas, passou a demorar apenas 15 a 20 minutos com um índice mínimo de perdas por rompimento do córion.

Para alimentar as larvas corretamente, como descrito por alguns pesquisadores (Freitas, 2001), era utilizado o sistema de colagem de ovos de traças em cartolina. Nesse sistema, pedaços de cartolina com dimensões 1,2 e 3 pol$^{2}$ eram oferecidos para grupos de 20 larvas de $1^{\circ}, 2^{\circ}$ e $3^{\circ}$ ínstares respectivamente (sendo 1 pol $^{2}$ equivalente a $2,5 \mathrm{~cm}$ x $2,5 \mathrm{~cm})$. Como a confecção desses cartões era um processo muito oneroso, foi desenvolvido um jogo de peneiras que, quando acoplado ao gargalo de um pequeno frasco com ovos de traças, permite que cada estádio larval seja alimentado com golpes (semelhantes ao de um saleiro de mesa) nesse frasco; o uso de diferentes malhas dessas peneiras, para cada ínstar, acelerou a etapa de alimentação da fase imatura.

Para se estabelecer uma produção operações que atendam uma demanda constante. Com a estrutura montada e conhecendo o período ideal de oviposição da espécie, foi desenvolvido um sistema baseado em módulos e no fato de que $C$. externa tem um período de pré-oviposição de pouco menos de 1 semana e oviposita bem durante até 60 dias. São utilizados 7 módulos de produção, com 6 deles em colheita e um em descanso (pré-oviposição).

A cada semana um novo módulo é montado e outro, de 7 semanas antes, é descartado. O sistema, desde a sua implantação, está delineado no esquema a seguir com os diferentes módulos indicados pelas letras de A a G (Figura 3).

As larvas são produzidas em potes plásticos de $300 \mathrm{ml}$, onde se colocam pedaços de papel absorvente, de maneira a aumentar a área disponível para os insetos se esconderem uns dos outros, com conseqüente diminuição do canibalismo. Em cada pote são colocados 20 ovos de 0 a 48 h; após 2 dias, os potes recebem ovos de Sitotroga cerealella, alimento fornecido a cada 3 ou 4 dias até o início da fase de prépupa. Na fase larval o alimento é controlado, de maneira a se obter um sucesso larval de apenas $25 \%$, ou seja, 1 em cada 4 ovos chegam a fase de pupa nesse processo, para assim, intencionalmente, incentivar o canibalismo entre as larvas e estimular a capacidade de busca dos predadores. constante, é preciso escalonar algumas

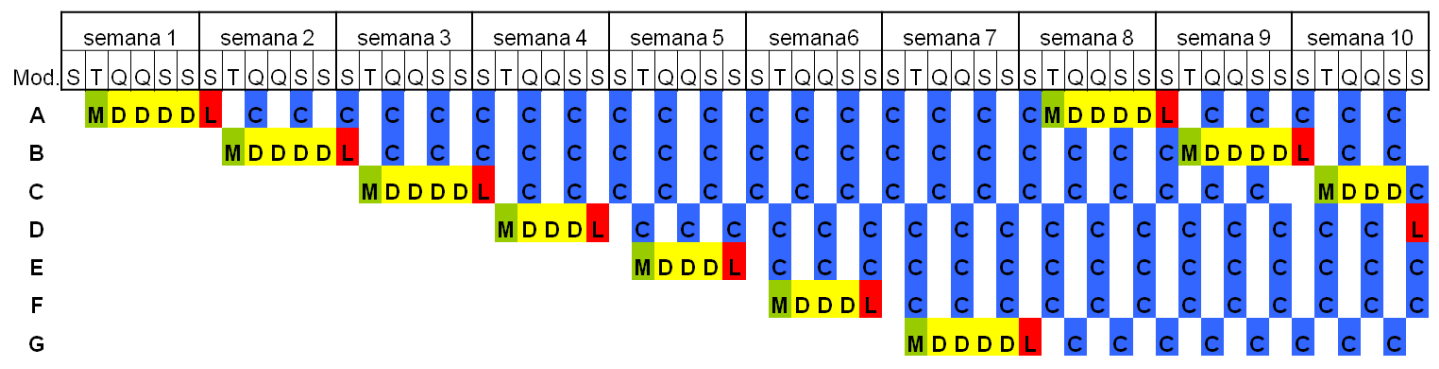

Figura 3. Esquema de escalonamento de produção de Chrysoperla externa em laboratório; (M) montagem; (D) descanso; (L) limpeza e descarte dos ovos; (C) coleta de ovos. 
Além de otimizar o uso dos ovos de traça fornecidos como alimento, essa tática reduz os custos de produção. Após a pupação todos os casulos são coletados e separados em uma câmara de emergência, que contribui para a troca de material genético dentro da população de laboratório.

\section{CONCLUSÃO}

Os aspectos biológicos observados de Chrysoperla externa permitem sua produção no sistema proposto, com manipulação dos adultos durante 49 dias e com os 7 primeiros sem coleta dos ovos.

As adaptações no sistema de produção permitem um ganho significativo em redução de custos e eficiência operacional.

\section{REFERÊNCIAS BIBLIOGRÁFICAS}

BEZERRA, C. E. S.; NOGUEIRA, C. F. H.; SOMBRA, K. D. S.; DEMARTELAERE, A. C. F.; ARAUJO, E. L. de. 2009. Crisopídeos (Neuroptera: Chrysopidae): aspectos biológicos, potencial de utilização e perspectivas futuras. Revista Caatinga, Mossoró, v. 22, n. 3, p. 1-5.

BEZERRA, G. C. D.; SANTA-CECILIA, L. V. C.; CARVALHO, C. F.; SOUZA, B. 2006. Aspectos biológicos da fase adulta de Chrysoperla externa (Hagen, 1861) (Neuroptera: Chrysopidae) oriunda de larvas alimentadas com Planococcus citri (Risso, 1813) (Hemiptera: Pseudococcidae) Ciência e Agrotecnologia, Lavras, v. 30, n. 4, p. 603-610.

CARVALHO, C. F.; SOUZA, B. 2000. Métodos de criação e produção de crisopídeos. In: BUENO, V.H.P. (Ed.). Controle biológico de pragas: produção massal e controle de qualidade. Lavras: UFLA, p. 91-109.

CARVALHO, C. F. ; CANARD, M. ; ALAUZET, C. 1996. Comparison of the fecundities of the Neotropical green lacewing Chrysoperla externa (Hagen) and the West-Palaeartic Chrysoperla mediterranea (Holzel) (Insecta: Neuroptera: Chrysopidae). Pure And Applied Resaerch In Neuropterology, p. 103-107.

DEBACH, F. 1974. Biological control by natural enemies. Cambridge: University Press, $323 \mathrm{p}$.

FREITAS, S.; FERNANDES, O. A. 1996. Crisopídeos em agroecossistemas. In: SIMPÓSIO DE CONTROLE BIOLÓGICO, 5., 1996, Foz do Iguaçu. Resumos... Foz do Iguaçu: EMBRAPA,CNPSO, p. 283-287.

FREITAS, S.; PENNY, N. 2001. The green lace-wings (Neuroptera: Chrysopidae) of Brazilian agro-ecosystems. Proceedings of the California Academy of Sciences, San Francisco, v. 52, n. 19, p. 245-398.

FREITAS, S. 2001. Criação de crisopídeos em laboratório. 1. ed. Jaboticabal: Funep. v. 300. 20 p.

LENTEREN, J. C. 2000. Greenhouse without pesticides: fact or fantasy? Crop Protection, Amsterdam, v. 19, p. 375384.

PARRA, J. R. P. 2007.Técnicas de criação de insetos para programas de controle biológico. Piracicaba: FEALQ, 137 p.

RIBEIRO, L. J. 1998. Características do desenvolvimento e potencial reprodutivo de Chrysoperla externa (Hagen, 1861) (Neuroptera Chrysopidae) sob diferentes dietas alimentares.. Dissertação (mestrado em Agronomia) Faculdade de Ciências Agrárias e Veterinárias, Universidade Estadual Paulista, Jaboticabal. 